Climate Dynamies (1995) 11:359-375

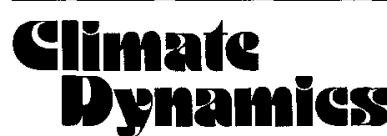

(c) Springer-Verlag 1995

\title{
The relationship between sea surface temperature anomalies and atmospheric circulation in GCM experiments
}

\author{
Viacheslav V. Kharin \\ Max-Planck-Institut für Meteorologie, Bundesstrasse 55, D-20146 Hamburg, Germany \\ Received: 14 June 1994/Accepted: 17 April 1995
}

\begin{abstract}
Several 19-year integrations of the Hamburg version of the ECMWF/T21 general circulation model driven by the monthly mean sea surface temperature (SST) observed in 1970-1988 were examined to study extratropical response of the atmospheric circulation to SST anomalies in the Northern Hemisphere in winter. In the first 19-years run SST anomalies were prescribed globally (GAGO run), and in two others SST monthly variability was limited to extratropical regions (MOGA run) and to tropics (TOGA run), respectively. A canonical correlation analysis (CCA), which select from two time-dependent fields optimally correlated pairs of patterns, was applied to monthly anomalies of SST in the North Alantic and Pacific Oceans and monthly anomalies of sea level pressure and $500 \mathrm{hPa}$ geopotential height in the Northern Hemisphere. In the GAGO run the best correlated atmospheric pattern is global and is characterized by north-south dipole structures of the same polarity in the North Atlantic and the North Pacific sectors. In the MOGA and TOGA experiments the atmospehric response is more local than in the GAGO run with main centers in the North Atlantic and North Pacific, respectively. The extratropical response in the GAGO run is not equal to the sum of the responses in the MOGA and TOGA runs. The artificial meridional SST gradients at $25^{\circ}-$ $30^{\circ} \mathrm{N}$ probably influence the results of the MOGA and TOGA runs. The atmopsheric modes found by the CCA were compared with the normal modes of the barotropic vorticity equation linearized about the 500 $\mathrm{hPa}$. winter climate. The normal modes with smallest eigenvalues are similar to the model leading variability modes and canonical patterns of $500 \mathrm{hPa}$ geopotential height. The corresponding eigenvectors of the adjoint operator, which represent an external forcing optimal for exciting normal modes, have a longitudinal structure with maxima in regions characterized by enhanced high frequency baroclinic activity over both oceans.
\end{abstract}

\section{Introduction}

The problem of large-scale air-sea interaction in middle latitudes frequently attracts the attention of meteorologists and climatologists attempting to use sea surface temperature (SST) anomalies as a significant predictor of climate on time scales of a month to a season. Namias $(1964,1978)$, for example, tried to relate the activity of blocking events in 1958-1960 over northern Europe to an anomalously cold SST off Newfoundland, and SST anomalies in the North Pacific to an anomalous winter circulation over North America. The subject of the role of extratropical SST anomalies in atmospheric circulation is rather controversial. Some authors have reported feedback relationships between Atlantic SST anomalies and monthly atmospheric circulation anomalies over Western Europe. In particular, Ratcliffe and Murray (1970) showed that cold SST anomalies in a key area in the North Atlantic south of Newfoundland are associated with blocking patterns over northern and Western Europe the following month whereas a warmer than usual ocean in the same area favors a more zonal circulation. On the other hand, Barnett et al. (1984) did not find statistsically significant indications that SST anomalies in North Atlantic could serve as a good predictor for seasonal surface air temperature anomalies over Europe and Asia.

Many papers published during recent years have been devoted to the study of atmosphere/ocean interactions in midlatitudes on seasonal and annual time scales by means of different techniques of statistical analysis (Dymnikov and Filin 1985a; Wallace and Jiang 1987; Wallace et al. 1990; Wallace et al. 1992; Zorita et al. 1992, to name a few). Summarizing the results of these studies, one might conclude that there is a largescale nonlocal relation between the atmosphere and the ocean in midlatitudes on these time scales. Leading patterns of atmospheric extratropical variability are statistically significantly correlated with extratropical SST anomalies. Lag correlations between observed time series of SST and different atmospheric parameters indicate that the atmosphere mainly leads the 
ocean on seasonal and annual time scales (Davis 1978; Wallace and Jiang 1987; Zorita et al. 1992). Atmospheric modes obtained by means of a singular vector decomposition technique (Wallace et al. 1992) or a canonical correlation analysis (Zorita et al. 1992) are similar to well-known North Atlantic and West Atlantic teleconnection patterns identified by Wallace and Gutzler (1981).

Numerous publications in which the sensitivity of the atmopsheric circulation to SST anomalies in midlatitudes is assessed by means of general circualtion models (GCMs) of different complexity (Pitcher et al. 1988; Palmer and Sun 1985; Lau and Nath 1990; Kushnir and Lau 1992) have shown that the physical processes involved in the formation of the atmospheric response are complicated. The theory of stationary Rossby-wave dispersion (e.g., Hoskins and Karoly 1981; Webster 1981) supplies us with a theoretical background on a possible stationary atmospheric response to stationary heating. The relation between SST anomalies and the heating in midlatitudes is, however, not obvious. Moreover, several experimental studies (Palmer and Sun 1985; Dymnikov and Filin 1985a,b; Lau and Nath 1990) suggested that transient eddies could play an essential role in the formation of largescale atmospheric anomalies. The geographical localization of zones of high baroclinicity due to zonal asymmetry of the basic atmospheric flow seems to be important, too (Ting 1991).

The problem of the relative importance of extratropical and tropical SST anomalies for the extratropical atmospheric circulation has been recently considered by a number of authors (e.g., Graham et al. 1994; Lau and Nath 1994). Graham et al. (1994) studied atmospheric variability in three GCM experiments which were made with the observed 1970-1988 monthly mean SST as the lower boundary condition for the atmospheric circulation. One GCM experiment was made with the globally prescribed SST (the GAGO run). In another two experiments the SST variability was limited to tropical regions (the TOGA run) and to extratropical regions (the MOGA run). Similar experiments but with another GCM and for a slightly different time period were carried out by Lau and Nath (1994). They produced four independent realisations, for each type of SST forcing (global, tropical and extratropical), increasing the statistical value of their results. A partical emphasis in both studies was made on the Pacific sector where the model atmospheric variability was compared with observations.

All of the GCM experiments mentioned were able to reproduce different aspects of the observed circulation variability with the best agreement if the tropical SST anomalies wered included. Graham et al. (1994) found some indications that the atmospheric response to SST anomalies in Pacific midlatitudes is still detectable. Particularly, the decadal shift in the mid-1970s was reproduced in each experiment with best results over the North Pacific in the TOGA run and over the North Atlantic and Europe in the GAGO and MOGA experiments.
The present study can be considered as a complementary one to the paper of Graham et al. (1994). The main motivation was to extend the analysis of coupled air-ocean modes in the GCM experiments to the North Atlantic region which was mainly neglected in the studies mentioned. Secondly, the atmospheric variability and the best correlated coupled modes in the GCM experiments are compared not with the observed variability as Graham et al. (1994) did but with each other. This allows the possibility that the atmospheric response to SST anomalies is still detectable but might be different or not correctly reproduced by the GCM compared to observed atmospheric anomalies. In this case the similarity between the observed and the model atmospheric anomalies would be weak.

Of particular interest is the question whether the atmospheric response depends linearly on the SST forcing in different regions, or whether the atmospheric response in the GCM experiment with the global SST forcing is a linear combination of the responses in the GCM experiments with locally limited SST variability. The assumption of linear behavior of the atmosphere with respect to SST variability in different geographical regions is indirectly implied when performing experiments like GAGO/MOGA/TOGA. If it is not the case, the atmospheric response found in GCM experiments with locally limited SST variability might inadequately describe the response in the GCM run with globally prescribed SST variability. The role of the meridional SST gradient in subtropical regions is also addressed in this study.

The possible dynamical mechanisms for the atmospheric response in the GCM experiments are discussed in the present study. To explain the discrepancies between the model and observed variability modes the barotropic normal mode analysis was performed (see e.g., Branstator 1985a,b). Normal modes are computed both for the model and observed basic states and compared with the leading modes of the atmospheric variability and with the atmopspheric response.

The receptor is organized as follows. Section 2 gives a short description of the GCM and of the experiments made with this model. The statistical method which were applied are also presented in this section. The atmospheric response in the North Atlantic area is examined in Section 3. The leading modes of the model atmospheric variability and the results of the canonical correlation analysis in the Northern Hemisphere are demonstrated in Section 4. Barotropic normal modes are described in Section 5 followed by a concluding discussion.

\section{Experimental design}

The Hamburg low resolution version of the ECMWF (European Center for Medium Range Weather Forecasts) spectral general circulation model ECHAM2 with triangular truncation of the spectral harmonic representation at wave number 21 was used for a number of multi-year integrations. The detailed description 
of the GCM can be found in Roeckner et al. (1992). The physical processes, such as radiation, cloud cover, large-scale condensation and deep convection schemes, turbulent vertical diffusion are parameterized. The deep convection and large-scale condensation schemes account for precipitation as rain or snow.

There were several 19-year GCM runs available for the analysis. These have already been described in detail by Graham et al. (1994). Here only a briefsummary of the GCM experiments is presented. In the first experiment referred to as the GAGO (Global Atmosphere - Globe Ocean), run the observed sea surface temperatures from the National Meteorological Center (USA) analysis were specified globally in 1981-1988 and near-globally in 1970-1980 for each month. The other integration, the MOGA (Midlatitude Ocean Global Atmosphere) run, was conducted in the same manner as the GAGO experiment, but the SST anomalies were prescribed only in midlatitudes (northwards of $30^{\circ} \mathrm{N}$ and southwards of $30^{\circ} \mathrm{S}$ ), whereas in the tropics the climatological values of SST were used. In the TOGA (Tropical Ocean - Global Atmosphere), run, the observed SST was prescribed in the tropics $\left(25^{\circ} \mathrm{S}-\right.$ $25^{\circ} \mathrm{N}$ ) and the climatological SST elsewhere. In addition, a 19-year CONTROL run with the climatological SST prescribed everywhere for each calendar month was also available for estimating the internal atmospheric variability in the absence of interannual SST forcing.

Monthly means in winter (December, January, February), altogether 57 months, were used in the analysis of the atmospheric variability. To verify the stability of the results to sampling errors the analysis war repeated for a five month winter season (NovemberMarch). The annual cycle defined as the 19-year mean for each calendar month was eliminated from the data.

The ECHAM2/T21 model reproduces the mean winter circulation in the Northern Hemisphere quite well. The climatology and the interannual atmospheric variability in the ECHAM2/T21 has been thoroughly studied by several authors (e.g., Roeckner et al. 1992; Barnett et al. 1991). All the runs deliver nearly the same long-term mean atmospheric circulation in the extratropical troposphere, and this is close to the observed winter climate. Ponater and König (1991) showed that the ratio of interannual atmospheric variability in the middle latitudes polewards of $30^{\circ} \mathrm{N}+\mathrm{S}$ latitude in the GAGO run to that in the CONTROL run exceeds unity at a statistically significant level only in a few regions, and there are even regions where the variance in the GAGO run is less than in the CONTROL run. Thus, the effect of the global SST forcing on the total extratropical variability seems to be small.

A canonical correlation analysis (CCA) with a limited number of Empirical Orthogonal Functions (EOFs) (e.g., Barnett and Preisendorfer 1987) was used to obtain the best correlated patterns of two fields, one of which was a SST anomaly field and to the other an atmospheric parameter. The result of the CCA depends on the number of EOFs retained. In particular, the canonical correlations tend to be artificially high if the number of EOFs is too large. One has to find a compromise between the wish to retain as much explained variance and consequently, as much of the potential signal as possible and the need to eliminate noise from the data. A number of preliminary tests with the CCA with different numbers of EOFs suggested that the first five leading EOFs retained for each field could be appropriate in our case.

A number of CCAs were produced with sea level pressure (SLP) in the North Atlantic region and 500 hPa geopotential height (H500) over the Northern Hemisphere and SST anomalies in different geographical regions such as the North Atlantic, North Pacific and the near global region northwards of $25^{\circ} \mathrm{S}$ where the observed SSTs were specified through the whole 19-year period. The statistical significance of the CCA results is defined by means of Monte-Carlo simulations. Two hundred CCAs for each GCM run with the data which were randomly rearranged in time were performed to estimate the level of correlations that would appear in the CCA by chance. The results of these simulatons are collected in Appendix A. To estimate systematical errors in canonical correlations due to sampling errors and to drive corrected unbiased values for canonical correlations a technique proposed by Glynn and Muirhead (1978) was applied. Appendix B gathers the results of this test for all GCM runs.

\section{The atmospheric response in the North Atlantic region}

Zorita et al. (1992) applied the canonical correlation analysis to observed SLP and SST monthly anomalies in the North Atlantic in winter 1951-1986, and obtained basically two meaningful pairs of canonical patterns. Since in the previous studies of Graham et al. (1994) and Lau and Nath (1994) the air-sea interactions were discussed in detail only in the Pacific sector, in this section the results of the CCA applied to SLP and SST from the GCM experiments for the North Atlantic region are presented. The SST field covers the area $14^{\circ} \mathrm{N}-64^{\circ} \mathrm{N} 90^{\circ} \mathrm{W}-5^{\circ} \mathrm{W}$. Nearly the same regions were used in the observational study of Zorita et al. (1992). The SLP field covers the area $0^{\circ} \mathrm{N}-90^{\circ} \mathrm{N}$ $100^{\circ} \mathrm{W}-10^{\circ} \mathrm{E}$.

Since there is no interannual SST variability almost in the whole region in study in the TOGA run, only the GAGO and MOGA experiments are considered in this section. The results of the CCA applied to SST in the tropical Atlantic $\left(25^{\circ} \mathrm{S}-25^{\circ} \mathrm{N}\right)$ and SLP in the North Atlantic region in the TOGA run appeared to be statistically insignificant. The first canonical correlation in this case is 0.49 which is statistically significant only at the level below $70 \%$. Thus, in the TOGA run there is no statistically stable relationship between North Atlantic SLP and tropical Atlantic SST.

The first five EOFs in the GAGO run explain about $87 \%$ of the total SLP variability and $72 \%$ of the SST variability in the region in study. In the MOGA run 

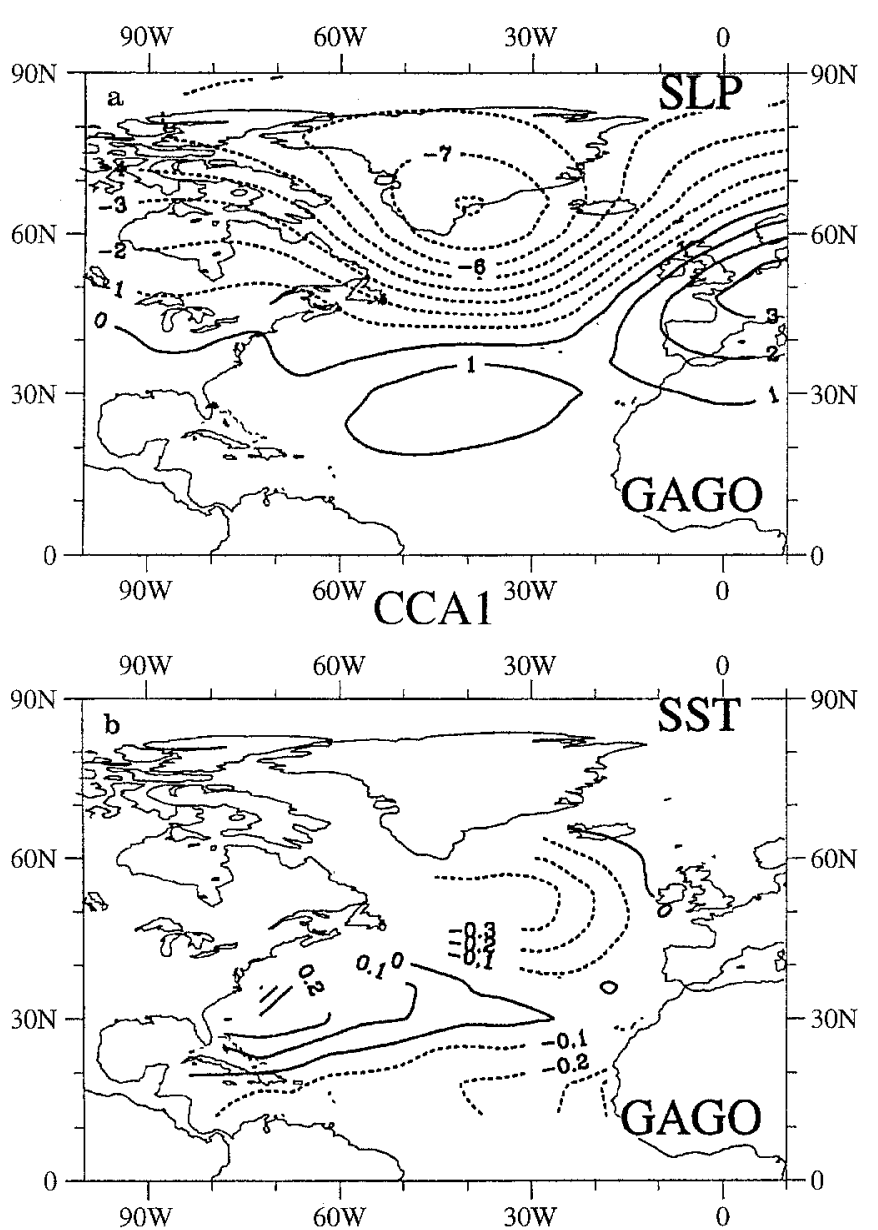

Fig. 1a-d. The SLP and SST first canonical patterns in the North Atlantic area in the GAGO run $\mathbf{a}, \mathbf{b}$, canonical correlation 0.66 and in the MOGA run $\mathbf{c}, \mathbf{d}$, canonical correlation 0.54. They explain $32 \%(\mathbf{a}$, SLP) and $21 \%(\mathbf{b}, \mathrm{SST})$ of the total variance in the

the amount of the variance explained by the first five EOFs is $80 \%$ for SLP and $78 \%$ for SST. The obtained first pairs of canonical patterns of SLP and SST are depicted in Fig. 1. The canonical patterns in the both experiments appeared to be stable with respect to the number of the EOFs retained in the analysis. Pattern correlations between the first canonical maps of SLP and SST obtained in the CCA with five EOFs retained for both fields and the corresponding maps obtained in the CCA with the EOF number in the range 4-7 exceed in all cases 0.99. Pattern correlations are still high $(\geq 0.92)$ if the results of the CCA for the 3 -month winter season (December-February) are compared to the corresponding results of the CCA for the 5-month winter season (November-March).

The best correlated patterns in the GAGO run with canonical correlation $0.66(99.5 \%$ statistically significant) are very similar to the first pair of canonical patterns calcualted for the observed data. The SLP pattern (Fig. 1a) explains 32\% of the total variance and is basically the first EOF in this region. It is characterized by a large scale north-south dipole with one center of about $8 \mathrm{mb}$ over south Greenland and another one in the central North Atlantic at $30^{\circ} \mathrm{N}$. Another positive
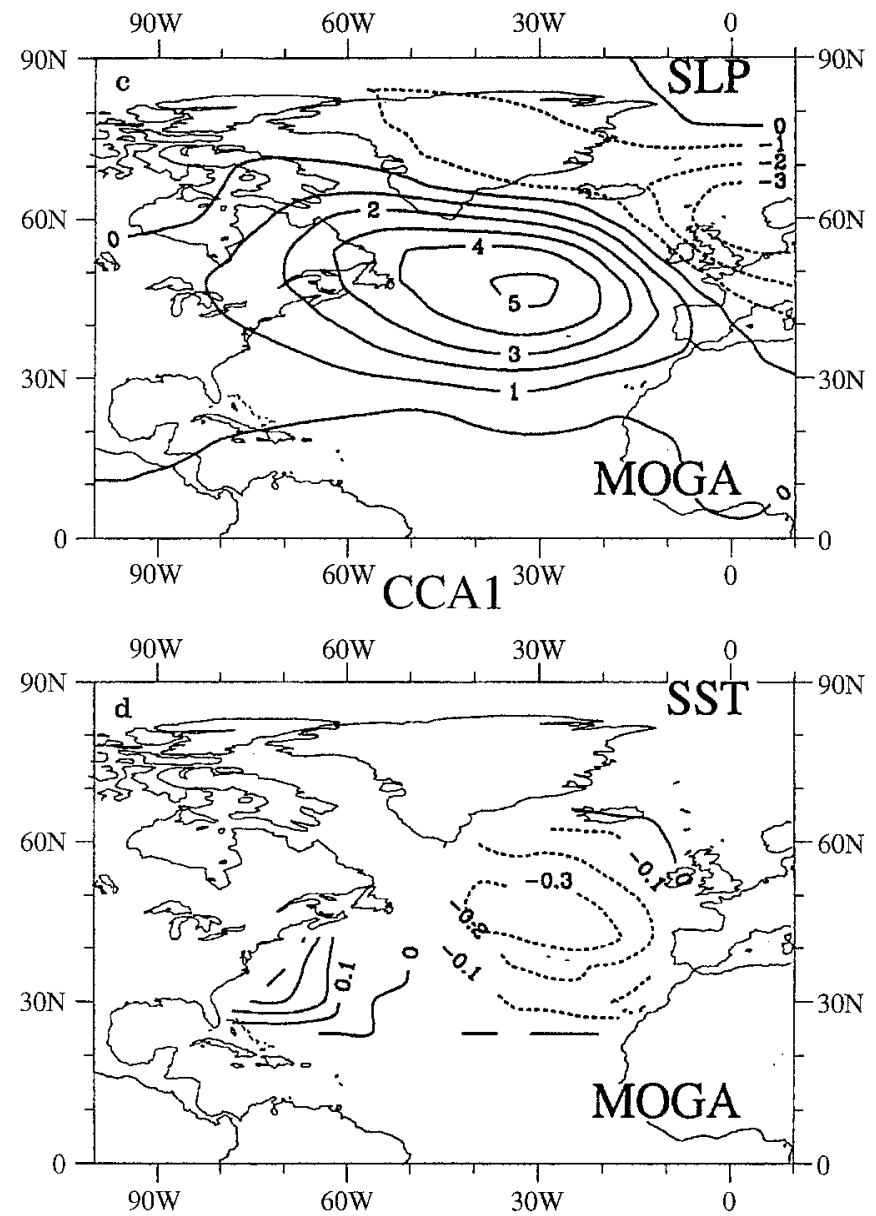

GAGO run and $15 \%$ (c, SLP) and $25 \%$ (d, SST) of the total variance in the MOGA run. Contour interval is $1 \mathrm{mb}$ for SLP and $0.1 \mathrm{~K}$ for SST

SLP anomaly of $3 \mathrm{mb}$ is over Europe. The atmospheric signal was found to be equivalent barotropic. The structure of the linear regression map of $500 \mathrm{hPa}$ geopotential height (H500) in the North Atlantic obtained on the base of the first canonical time component of SST (not shown) in very similar to the structure of the SLP pattern with a pattern correlation above 0.8 .

The SST canonical pattern (Fig. 1b) explains $21 \%$ of the total variance and contains three regions with SST anomalies of high amplitude. Negative SST anomalies are placed south of Greenland at $55^{\circ} \mathrm{N} 40^{\circ} \mathrm{W}$ and west of North Africa + Europe at $15^{\circ} \mathrm{N}$. A positive center is situated at the American coast between Newfoundland and the Florida peninsula.

From observational studies (e.g., Zorita et al. 1992) it is known that the atmospheric anomalies lead the SST anomalies in the extratropics on monthly time scales. The results of the GCM runs with prescribed SST, where the atmosphere anomalies occur at best simultaneously with SST variations or lag behind them, demonstrate the possible feedback from the SST on the atmospheric circulation. Assuming that the atmospheric response found in the North Atlantic in the GAGO run in terms of the first canonical pair of pat- 
terns represents correcly the atmopsheric reaction then such a response would support the atmospheric anomalies which are known from observarions to be responsible for the SST anomalies in the North Atlantic of the same structure as in the first SST pattern.

The linear relationship between SLP and SST in the North Atlantic in the MOGA run is weaker than in the GAGO run. The canonical correlation for the first pair of SLP and SST patterns in the MOGA run is 0.54 which is statistically significant only at the $80 \%$ level. The SLP pattern (Fig. 1c) explains $15 \%$ of the total variance and differs significantly from the SLP pattern in the GAGO run. A positive large scale SLP anomaly of $5 \mathrm{mb}$ is located over the central North Atlantic with the center at $45^{\circ} \mathrm{N} 30^{\circ} \mathrm{W}$. A negative SLP anomaly of $3 \mathrm{mb}$ is found over Northern Europe. The first SST pattern (Fig. 1d) is responsible for about $25 \%$ of the total SST variability in the North Atlantic northwards of $25^{\circ} \mathrm{N}$. This pattern resembles the first canonical SST map in the GAGO run in the corresponding region. However the SST anomalies in the MOGA run are more zonally orientated than in the GAGO run. The positive SST anomaly is compactly located at the US coast. The negative SST anomaly is placed slightly east- and southwards of the position of the negative anomaly in the GAGO pattern.

Since the first canonical correlation in the MOGA run is relatively weak, one might think that a statistically stable linkage between SLP and SST anomalies in the North Atlantic occurs only in the GAGO run. In the following section we will show that the atmospheric patterns found in the North Atlantic are parts of the global atmospheric signal. Thus, the atmospheric response found in the North Atlantic region can be, at least partly, a remote response to SST anomalies in other geographical regions.

\section{Atmospheric signal in the Northern Hemisphere}

\subsection{The leading modes of atmospheric variability in the GCM runs}

Before the results of the CCA are presented we examine the leading modes of the winter time atmospheric variability in the Northern Hemisphere in the GCM runs in terms of EOFs and compare them with the observed variability modes. The EOFs were calculated as the eigenvectors of the covariance matrix. The principal components have been normalized by unity so that the EOF maps represent the "typical" strength of the atmospheric variability.

The first EOFs of Northern Hemisphere H500 in the GAGO, MOGA, TOGA and CONTROL runs are depicted in Fig. 2. The general structure of the all EOFs is similar, having negative geopotential height anomalies over the northern parts of the oceans and in the polar regions and positive height anomalies roughly southwards of the negative anomalies. Anomalies of maximal amplitude are located in the North Atlantic sector. The pattern correlation between the first EOF in the CONTROL run and the other first EOFs exceeds in all cases 0.9. A more thorough analysis reveals some differences in the structure of the EOFs. In the GAGO run the zero line between positive and negative anomalies in the North Atlantic is placed slightly further south than in the other runs. The first EOF of the MOGA run has a more zonally symmetric structure. In the TOGA run the positive height anomaly in the North Pacific has the largest amplitude over $40 \mathrm{gpm}$.

The absolute and relative explained variances of the first 10 EOFs in the GCM experiments are shown in Fig. 3. In the GAGO run the first EOF has the largest amplitude and explains the largest portion of the total variance in relative units $(26 \%)$ as well as in absolute values. The second EOF in the GAGO run explained less the half the variance $(14 \%)$. The EOF spectra in the MOGA and TOGA runs are flatter. The amplitude of the first EOF (19\% of the total variance) in the MOGA run is the smallest among all the GCM experiments. The first EOF of the TOGA run is of larger amplitude than in the MOGA run but is weaker than in the GAGO and CONTROL experiments and is responsible for $22 \%$ of the total variability. The leading in the MOGA and TOGA runs are less dominant than in the GAGO run. The ratio of the variance explained by the first EOF to the variance explained the second EOF in the MOGA and TOGA runs is about $1.5 \mathrm{com}-$ pared to 1.9 in the GAGO experiment. The first five EOFs explain about $60 \%$ of the total variability in all GCM runs.

The second EOFs in the GAGO, TOGA and MOGA runs (not shown) have the strongest anomalies in the North Pacific/North America sector. They are similar to the PNA pattern described by Wallace and Gutzler (1981). Positive height anomalies are located in the tropical North Pacific and over the northern part of the North American continent, and negative height anomalies are placed over the northern part of the North Pacific and over southeast North America. Such a pattern is missing in the CONTROL run. The second EOF in the CONTROL experiment has a wave train structure with anomalies spreading from the western North Pacific over the north pole to the central North Atlantic.

For comparison the first two EOFs calculated for observed monthly means of $\mathrm{H} 500$ in the region north of $20^{\circ} \mathrm{N}$ in $1970-1987$ in winter (provided by NCAR) are shown in Fig. 4. The first EOF of the observed atmospheric variability has the main center over the North Pacific and differs significantly from the leading EOFs in the GCM runs. The amplitude of the positive anomaly in the North Pacific is over $90 \mathrm{gpm}$ which exceeds substantially the amplitude of the height anomalies in this region in the GCM runs. The negative anomaly in the northern part of the North Atlantic is, on the contrary, of much smaller amplitude than in the GCM experiments. The second observed EOF has some similarity with the model first EOFs in the North Atlantic region. The pattern correlation between the observed second EOF and the first EOF in the CON- 

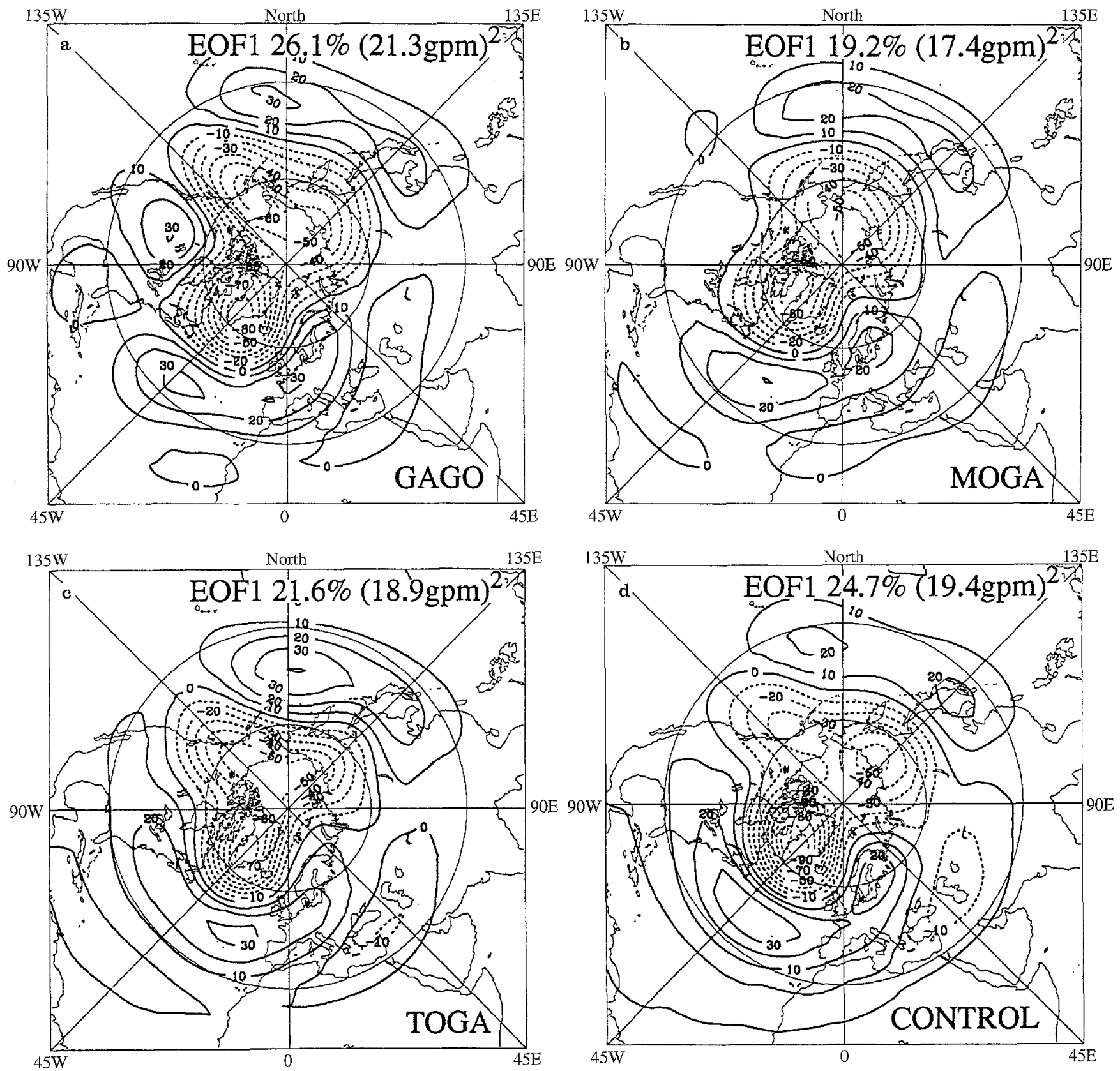

Fig. 2a-d. The first EOFs of Northern Hemisphere H500 in winter in the a GAGO; b MOGA; c TOGA and d CONTROL runs. They explain $26.1 \%, 19.2 \%, 21.6 \%$ and $24.7 \%$, respectively. Contour interval 10 gpm

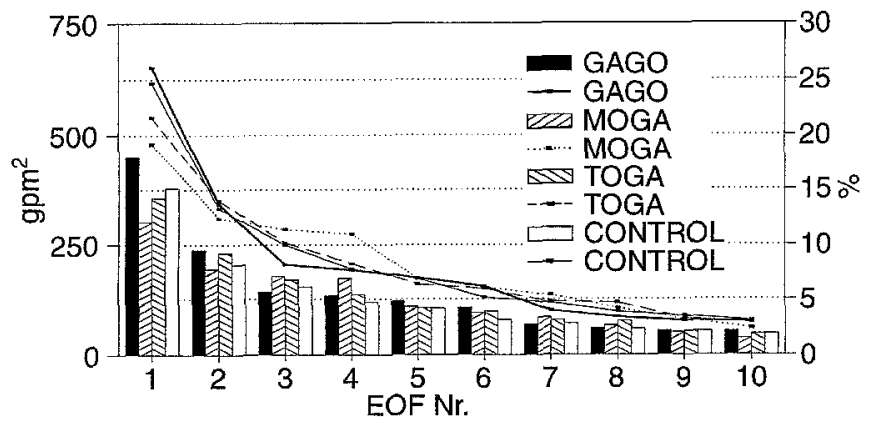

Fig. 3. The explained variances of the first 10 EOFs of Northern Hemisphere $\mathrm{H} 500$ in winter in absolute values $\mathrm{gpm}^{2}$ (bars) and in relative units \% (lines) in the GAGO, MOGA, TOGA and CONTROL runs
TROL run is 0.68 in the Northern Hemisphere north of $20^{\circ} \mathrm{N}$. The first EOF is not as dominant compared to the GCM experiments. The explained variances of the first two EOFs are $21 \%$ and $16 \%$, respectively.

Thus, the leading modes of atmospheric variability in the GCM differ significantly from those in the observations. A variability mode like PNA is the first EOF in the observations and the second EOF in the GAGO, MOGA and TOGA runs. A variability mode with the strongest anomalies in the North Atlantic is the first EOF in the GCMs and only the second EOF in the observations. In view of this fact the spatial structure atmospheric response in the GCM experiments might be improperly reproduced compared to the observed 

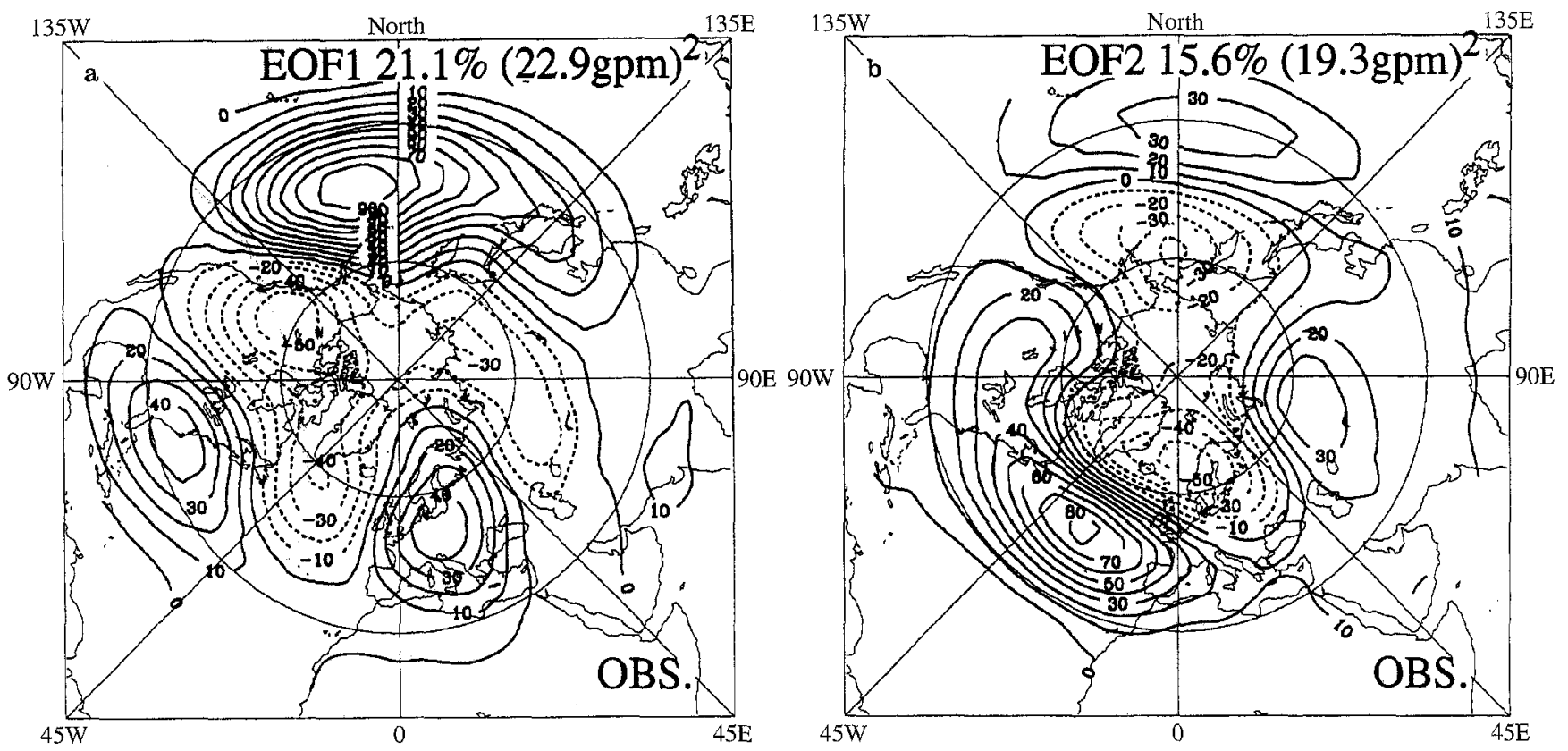

Fig. 4a, b. The first and the second EOFs of Northern Hemisphere H500 variability in winter in the observed in 1970-1987 data provided by NCAR. They explain $21 \%$ and $16 \%$ of the total variance, respectively

atmosphere. Therefore, the results of the GCM experiments might be of little relevance if compared directly with the observed atmospheric anomalies. Nevertheless, it still might be interesting to know the potential effect of the SST forcing in different geographical regions on the atmospheric variability in the GCM and to understand the dynamical mechanisms which could be important for the atmospheric response in the observed atmosphere/ocean coupled system.

\subsection{Atmospheric response in the GAGO run}

The first two best correlated pairs of canonical patterns of Northern Hemisphere H500 and near global SST are shown in Fig. 5. The SST field was taken north of $25^{\circ} \mathrm{N}$ where the observed SST anomalies were prescribed during the whole 19-year period. The canonical patterns appeared to be relatively stable and do not change significantly if the number of EOFs retained in the CCA is varied in the range of 3-7. The results of the CCA for the 5-month winter season are also essentially the same.

The first H500 canonical pattern (Fig. 5a) explains $21 \%$ of the total variance. It has the same structure in the North Atlantic sector as the SLP pattern shown in Fig. 1a. Negative height anomalies are found over the northern parts of the North Atlantic and North Pacific and in the polar regions. Positive anomalies are located over North America, over Europe and in the subtropical regions over both oceans. In the first SST pattern (Fig. 5b) one can recognize three centers of action in the North Atlantic which have already been found in the North Atlantic SST pattern in the previous analysis. A negative SST anomaly in the North Pacific is lo- cated in the northeastern part of the ocean with the maximum at $40^{\circ} \mathrm{N} 175^{\circ} \mathrm{E}$. Positive SST anomalies are placed south of the negative SST anomaly in the $20^{\circ}$ $30^{\circ} \mathrm{N}$ latitude band and at the Pacific coast of the USA. Another SST maximum of $0.5 \mathrm{~K}$ is located in the eastern tropical Pacific. The extratropical SST anomalies in the North Atlantic and North Pacific at the eastern continental coasts are basically associated with the variations of the meridional SST gradient. The explained variance of the first canonical SST pattern is less than $9 \%$. This map is not a typical El Niño pattern which is the dominant mode of the global interannual SST variability.

In the following the first canonical coupled H500SST mode will be referred to as the GAGO1 mode. The first canonical correlation is over 0.66 which is statistically significant at the $98.5 \%$ level. The corrected unbiased estimate of this value, according to Glynn and Muirhead's test (1978), is 0.54 with $95 \%$ significance interval $0.33-0.70$. The first canonical mode in the GAGO run does not change significantly if the CCA is applied to Northern Hemisphere H500 and to SST anomalies in the North Atlantic or in the North Pacific, or to tropical or extratropical SST anomalies. The pattern correlation between first canonical maps in all cases is of order of $0.8-0.9$ for H500 maps in the Northern Hemisphere and 0.7-0.9 for SST maps in the corresponding regions. Both the North Atlantic and North Pacific SST anomalies in midlatitudes contribute to the atmospheric response as in the GAGO1 pattern.

Since the first canonical pattern of H500 in the GAGO experiment is very similar to the leading EOF in this run (the pattern correlation is 0.89 ) one might think that this pattern is only an artificial result of lin- 


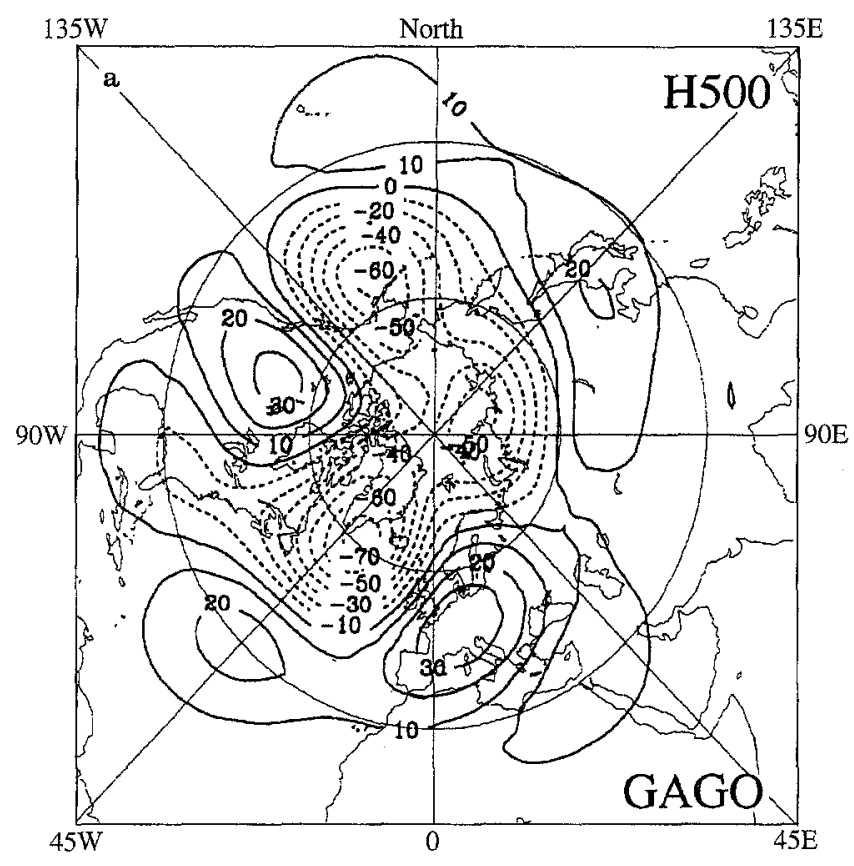

CCA1

90E $120 \mathrm{E} \quad 150 \mathrm{E} \quad 180 \quad 150 \mathrm{~W} \quad 120 \mathrm{~W}$ 90W $60 \mathrm{~W}$ 30W 0

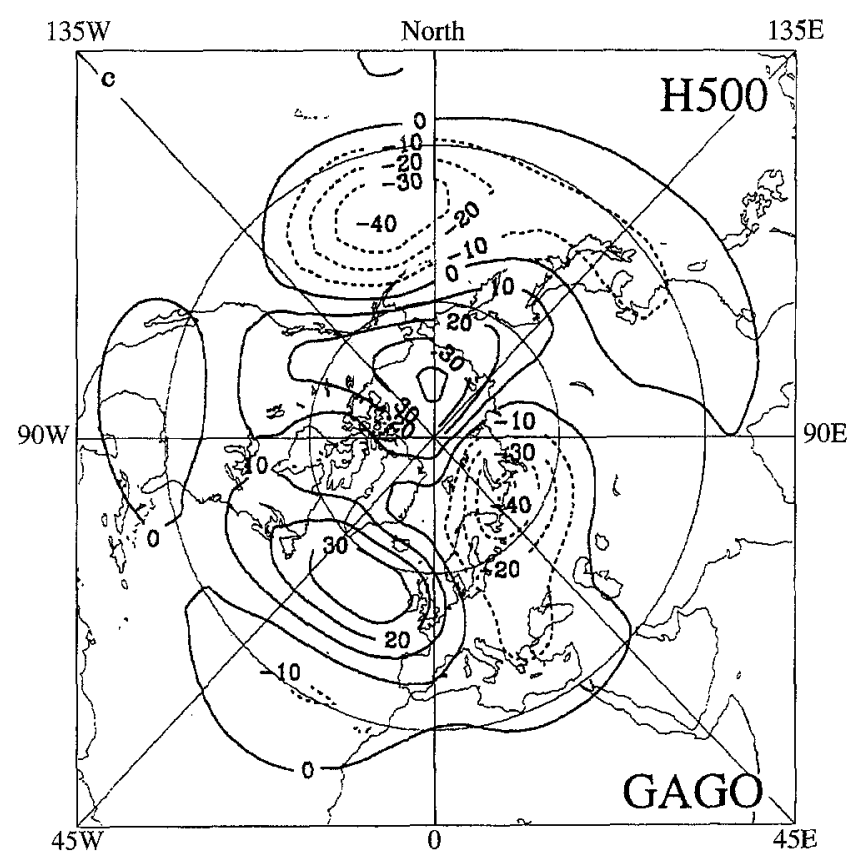

CCA2

$90 \mathrm{E} \quad 120 \mathrm{E} \quad 150 \mathrm{E} \quad 180 \quad 150 \mathrm{~W}$ 120W $90 \mathrm{~W}$ 60W $30 \mathrm{~W} \quad 0$

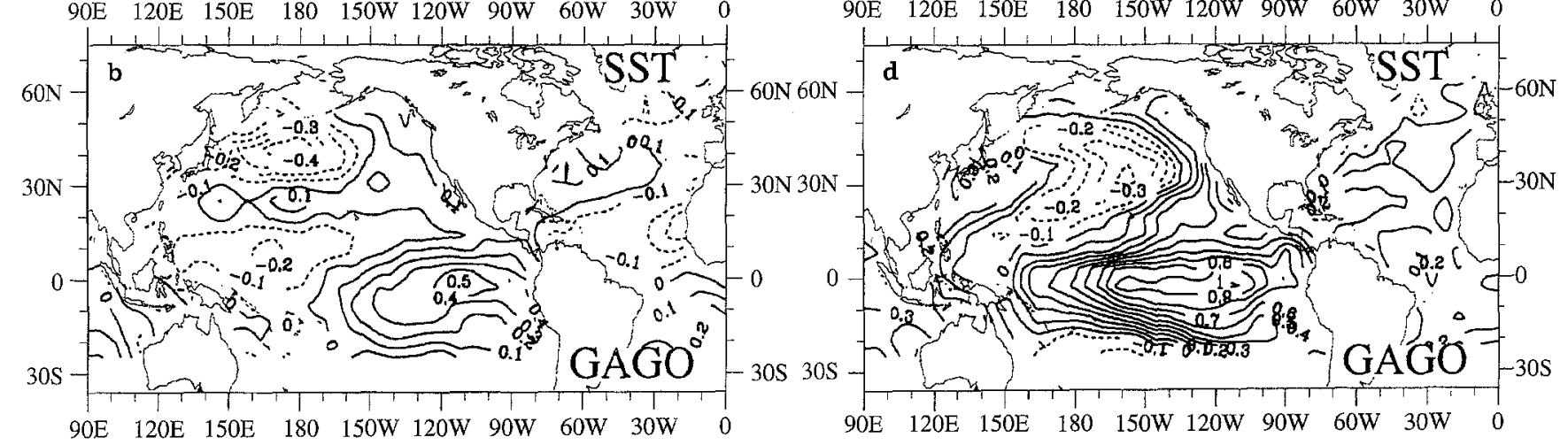

Fig. 5a-d. The patterns of the first two canonical pairs of Northern Hemisphere H500 (a, c, contour interval $10 \mathrm{gpm}$ ) and SST north of $25^{\circ} \mathrm{S}$ (b, d, contour interval $0.1 \mathrm{~K}$ ) in the GAGO run.

The first canonical patterns explain 21\% (H500) and 9\% (SST) of the total variance. The second canonical patterns explain $9 \%$ (H500) and 40\% (SST) of the total variance

ear projections on the dominant mode of the GCM. To estimate the probability of the fact that canonical patterns are similar to the dominant variability modes by chance, we computed Monte-Carlo simulations, as described in Appendix A, pattern correlations between the first canonical pattern of H500 and the first EOF of H500. In more than $97 \%$ of all cases the obtained spatial correlation was smaller than 0.89 . The probability of high spatial correlation between the first canonical pattern and the first EOF and high canoncial correlation in Monte-Carlo simulations was even lower. In particular, none of $200 \mathrm{CCA}$ cases exhibited a first canonical correlation higher than 0.60 and a spatial correlation higher than 0.75 .

The typical El Niño pattern in the SST field appeared to be the second canonical pattern (Fig. 5d) which explains more than $40 \%$ of the total SST variance. There is a strong positive SST anomaly up to $1 \mathrm{~K}$ over the central and eastern tropical Pacific and a negative SST anomaly in central midlatitudes of the North Pacific Ocean. The atmospheric signal related to this SST pattern with the canonical correlation 0.60 is shown in Fig. 5c. The second canonical H500 pattern explains about $9 \%$ of the total variance and consists of negative anomalies of $40 \mathrm{gpm}$ in the North Pacific area and over the Barents Sea and weaker positive anomalies over the North Atlantic and over the east Sibirian Sea. In the North Pacific/North America sector the second canonical pattern remains the Pacific North America (PNA) pattern with the positive height anomalies in the tropical North Pacific and over northern North America and negative anomalies in the extratropical North Pacific and in the subtropical area of North America. Hereafter this mode will be called the GAGO2 mode.

The GAGO1 mode is only weak related to the prominent SST anomalies in the tropical Pacific. The correlation between the SST index defined as SST av- 
eraged each month over the region $150^{\circ} \mathrm{W}-90^{\circ} \mathrm{W}, 5^{\circ} \mathrm{S}-$ $5^{\circ} \mathrm{N}$ (the ENSO3 region) and the corresponding canonical time series of SST and H500 is only about $0.2-$ 0.3 . The second canonical time component of SST is, on the contrary, very well correlated with the SST index $(\sim 0.9)$. The correlation of the second canonical time series of H500 with the SST index is somewhat weaker $(\sim 0.5)$ but still higher than for the first canonical mode.

A characteristic feature of the extratropical SST anomalies in the GAGO1 mode is their longitudinal structure in the eastern parts of the both basins. These regions are known for the most significant transport of vorticity and heat into the extratropics. Lau (1988) showed on the base of observations that the barotropic forcing by synoptic scale disturbances is positively correlated with the monthly averaged flow patterns. The variations of the SST meridional gradients associated with the SST anomalies in these regions are presumably related to the variability of the storm tracks which are expected to exert a considerable influence on the seasonal and interannual circulation.

The development of the atmospheric response to SST anomalies during the first several weeks and the establishment of the stationary response in the ECHAM2/T21 model was examined by Kharin (1995). The SST anomalies used in the SST sensitivity experiments were derived from the first canonical SST pattern in the North Atlantic in the GAGO run. The stationary atmospheric signal in these experiments was consistent with the GAGO1 mode. In the first 1-2 weeks the atmospheric response is located in the vicinity of the heat source and is highly baroclinic with positive (negative) height anomalies over and downstream of positive (negative) SST anomalies in the upper troposphere and height anomalies of opposite sign at the surface. After 2-3 weeks the atmospheric response reaches its final amplitude. The equivalentbarotropic component becomes dominant in the stationary signal far away from the heat sources. The structure of the equivalent-barotropic response depends on the internal atmospheric normal modes and on the structure of the external forcing. This point in addressed in Section 5.

\subsection{Atmospheric response in the MOGA and TOGA runs}

With respect to the signal found in the GAGO run there are several possibilities for the atmospheric response behavior in the MOGA and the TOGA runs:

1. If only extratropical SST anomalies are essential for exciting the global dominant GAGO1 mode then one would expect the same signal in the MOGA run.

2. If, on the contrary, tropical SST anomalies play the most important role for the GAGO1 mode, then the TOGA run should reproduce this signal.

3. If none of these runs reproduces the GAGO1 mode then both tropical and extratropical SST anomalies contribute to the atmospheric response as in the GAGO1 mode. In the case of the linear behavior one would expect that the linear combination of atmopsheric anomalies in the MOGA and TOGA runs would result in the same signal as in the GAGO experiment.

4. If the last possibility still fails to explain the GAGO1 mode then the problem becomes more complicated, since nonlinear interactions between midlatitudes and tropics are important for the atmospheric response.

5. An incorrect representation of the SST gradient at $25^{\circ} \mathrm{N}-30^{\circ} \mathrm{N}$ in the MOGA and TOGA runs could also influence the atmospheric response in these experiments.

The first canonical patterns of Northern Hemisphere H500 and of extratropical or tropical SST in the MOGA and TOGA runs are shown in Fig. 6. The canonical correlation between corresponding time series in the MOGA run is 0.61 . This is weaker than in the GAGO run but still statistically significant at the $97 \%$ level. The corrected unbiased correlation (Appendix B) is 0.49 which is also smaller than in the GAGO run. The H500 pattern (Fig. 6a) has strong anomalies in the North Atlantic sector and explains variance less (13\%) than the first canonical pattern in the GAGO experiment. It will be called hereafter the GAGO1 mode. In the North Atlantic region the structure of the H500 pattern is similar to the structure of the first canonical SLP pattern shown in Fig. 1c.

Although the distribution of SST anomalies in the first canonical pattern in the MOGA run (Fig. 6b) is similar in the extratropics to that in the first SST canonical pattern in the GAGO run, more thorough analysis reveals some differences. The SST anomalies in the first canonical pattern in the MOGA run are more zonally oriented compared to the extratropical SST anomalies in the first canonical SST map in the GAGO run. The positive SST anomaly in the western North Pacific is stronger in the MOGA run than in the GAGO experiment. The zero line between positive and negative SST anomalies in the western North Pacific in the MOGA run is situated slightly north of its position in the GAGO experiment. The meridional SST gradients associated with the SST anomalies in the GAGO1 and MOGA1 SST patterns are substantially different, especially in the $25^{\circ} \mathrm{N}-30^{\circ} \mathrm{N}$ latitude band.

The strongest atmospheric response in the MOGA run has a quite different structure from that in the GAGO experiment. It seems that the heat and vorticity forcing associated with a slightly different SST anomaly distribution in the MOGA run excites a completely different type of atmospheric mode than in the GAGO run. The SST anomalies in the MOGA run are only weakly, if at all, related to the like GAGO1 mode of atmospheric variability. Correlation coefficients between SST anomalies at each grid point and the time series associated with the GAGO1 mode obtained are less than 0.2 in the MOGA experiment.

The strongest signal in the TOGA run is again from the GAGO1 mode. The first canonical H500 pattern in 


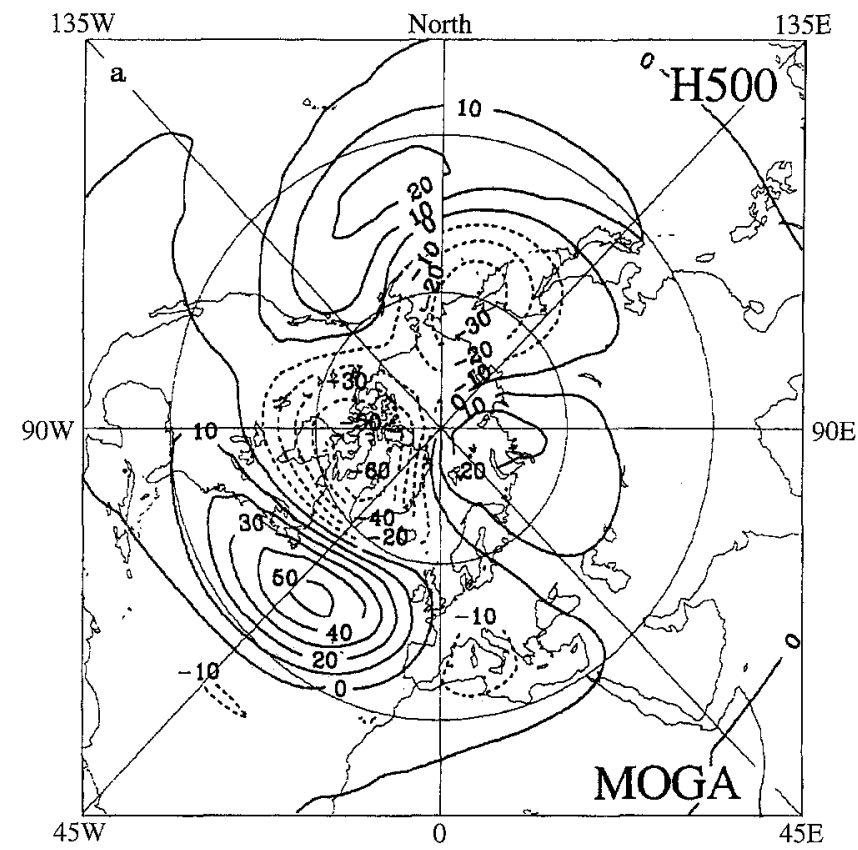

CCA1

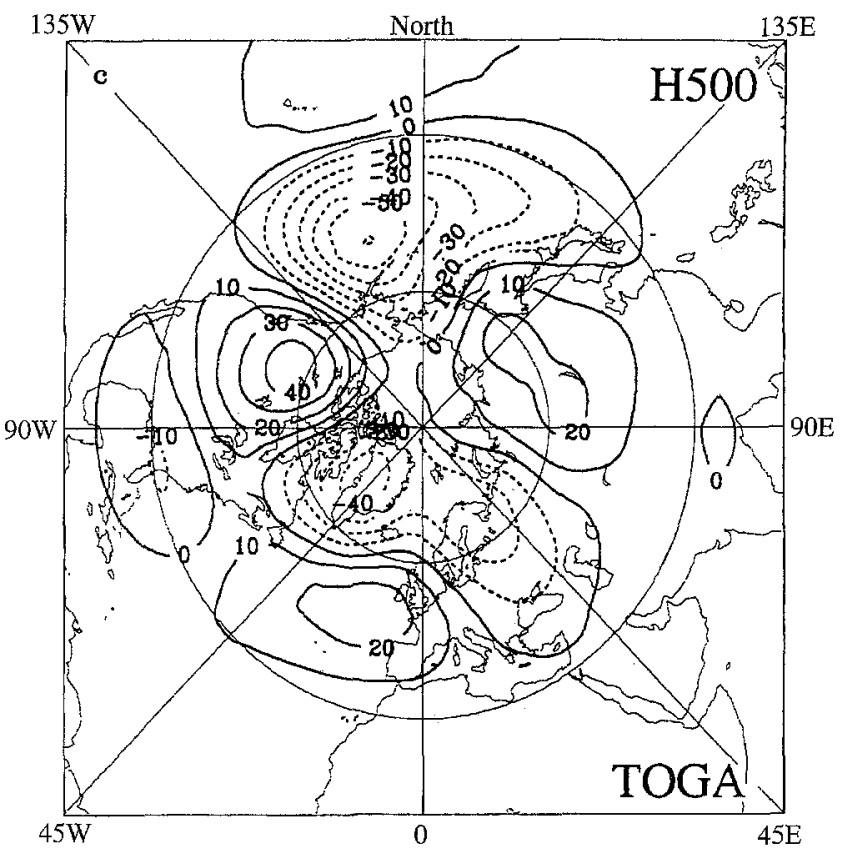

CCA1

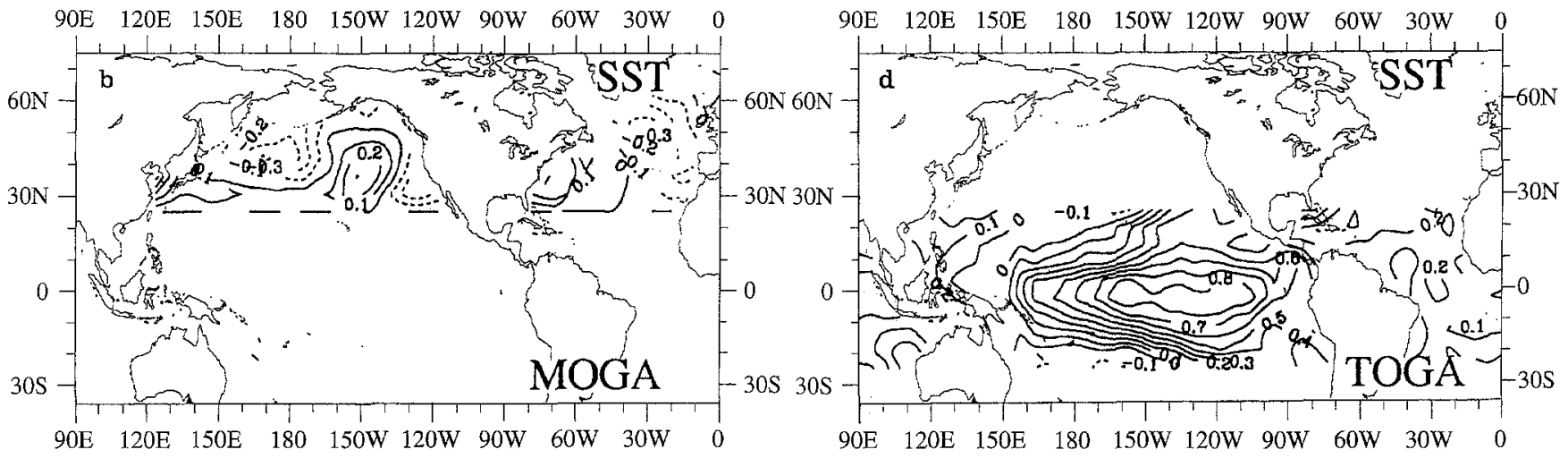

Fig. 6a-d. The patterns of the first canonical pairs of Northern Hemisphere H500 and extratropical (tropical) SST in the MOGA (TOGA) run. They explain $13 \%$ (a, H500) and $11 \%$ (b, SST) of the total variance in the MOGA run and 14\% (c, H500) and $41 \%$ (d, SST) of the total variance in the TOGA run. Contour interval is $10 \mathrm{gpm}$ for $\mathrm{H} 500$ and $0.1 \mathrm{~K}$ for SST the TOGA run (Fig. 6c) is similar to the second canonical pattern in the GAGO experiment (the GAGO2 mode in Fig. 5c) which is supposed to be associated with the El Niño phenomenon. This mode will be called the TOGA1 mode. The negative atmospheric anomaly over the North Pacific in the TOGA run is stronger than in the GAGO experiment and its center is shifted slightly northwards compared to the GAGO2 mode. The positive atmospheric anomaly over North America is more strongly developed than in the GAGO2 mode, increasing the resemblance of this mode to the PNA pattern of Wallace and Gutzler (1981). The structure of atmospheric anomalies over the North Atlantic sector in both experiments is also different. The first canonical SST pattern in the TOGA run (Fig. 6d) looks like the second SST canonical pattern in the GAGO experiment. Both patterns have strong positive SST anomalies in the central and eastern tropical Pacific. The correlations of the time series of the TOGA1 mode with the ENSO3 SST index defined above are 0.51 for H500 and 0.78 for SST.

The MOGA and TOGA runs do not reproduce the atmospheric signal found in the GAGO run as the first canonical pair of patterns. Assuming that the influence of SST on the atmosphere is linear, i.e., the atmospheric response to the SST anomalies in the GAGO run is the sum of the responses to SST anomalies in the middle latitudes and in the tropics, one might expect the same results as in the GAGO run if the CCA is applied to the sum of the atmospheric anomalies from the MOGA and the TOGA runs and to the global SST field. However, the first canonical pattern of the linearly combined H500 fields (not shown) appeared to be quite different from the GAGO1 mode. It is rather similar to the GAGO2 mode or to the TOGA1 mode. The corresponding SST pattern resembles the EI Niño mode. Therefore the atmospheric response in the linearly combined data is different from the GAGO1 


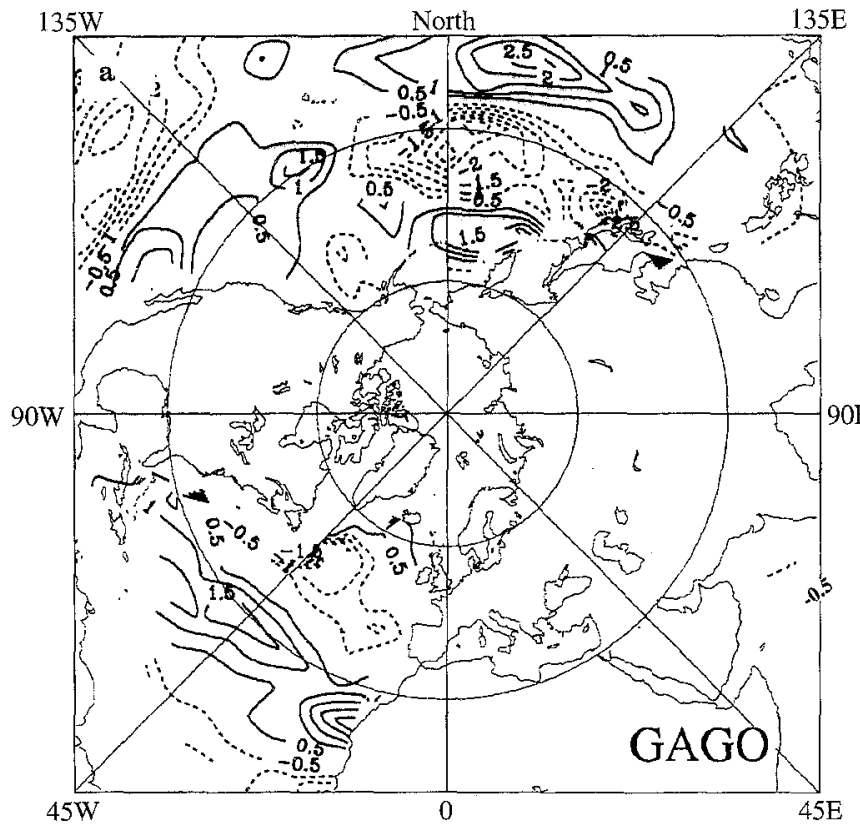

Fig. 7a, b. The distribution of linear regression coefficients between the time component of the first canonical pattern of Northern Hemisphere H500 and meridional SST gradient in a the GAGO run and between the time component of the first canoni-

mode and it seems that nonlinear interactions between midlatitudes and tropics play an important role in the atmospheric circulation and its response to SST anomalies.

\subsection{Atmospheric circulation and SST gradient}

Palmer and Sun (1985) assumed that the transient eddies could be of decisive importance for the extratropical atmospheric response. Since the baroclinic activity depends partly on the SST gradients, a wrong representation of the meridional SST gradient near $30^{\circ} \mathrm{N}$ in the MOGA and the TOGA runs could distort the atmospheric response in these experiments. At this latitude the observed and climatological SST values come together in these runs so that artificial meridional SST gradients arise in this region.

To clarify the relationship between atmospheric anomalous circulation and the SST gradient, the linear regression coefficients between the time series of the first canonical patterns of $\mathrm{H} 500$ in the GAGO and MOGA runs and the meridional SST gradient at each grid point in the Northern Hemisphere were computed. The obtained distributions of the region coefficients are shown in Fig. 7. The GAGO run reveals a relatively strong relation between the GAGO1 atmospheric mode and SST gradients in the North Atlantic at $20^{\circ} \mathrm{N}-30^{\circ} \mathrm{N}$ and at about $45^{\circ} \mathrm{N}$ off Newfoundland as well as in the central and western North Pacific at $15^{\circ} \mathrm{N}$ and at $30^{\circ} \mathrm{N}$ (Fig. 7a). The MOGA1 mode is related to a relatively strong SST gradient anomaly in the western North Atlantic and the central North Pacific north of $30^{\circ} \mathrm{N}$.

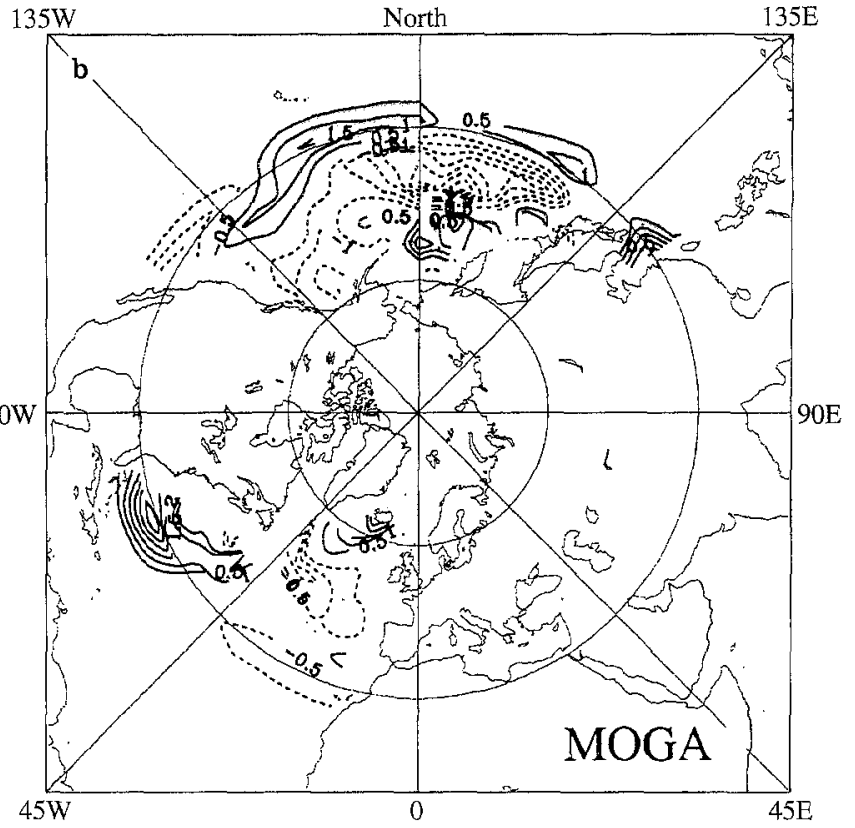

cal pattern of Northern Hemisphere $500 \mathrm{hPa}$ geopotential height and meridional SST gradient in $\mathbf{b}$ the MOGA run. Contour interval is $0.5 \cdot 10^{-7} \mathrm{~K} / \mathrm{m}$. Labels are multiplied by $10^{7}$

The main anomalies of the SST gradient which are related to the MOGA1 mode are placed slightly further northwards of their position in the GAGO run. Particularly, the negative SST gradient anomaly in the western and central North Pacific in the MOGA is located fully north of $30^{\circ} \mathrm{N}$ whereas in the GAGO run it is spreading from about $20^{\circ} \mathrm{N}$ to $45^{\circ} \mathrm{N}$. A strong positive SST gradient anomaly in the MOGA run is located in the North Atlantic at the US coast and in the central North Pacific at $25^{\circ} \mathrm{N}-30^{\circ} \mathrm{N}$, i.e., exactly in the regions where the observed SST anomalies occur together with the climatological SST values. In the GAGO run the subtropical SST gradient anomaly in the North Atlantic is of more moderate amplitude than in the MOGA run and covers the whole area between the North American coast and the African continent at $15^{\circ} \mathrm{N}-30^{\circ} \mathrm{N}$.

\section{Normal modes of the barotropic operator}

The atmospheric anomalies produced in the GCM experiments are of large scale and equivalent barotropic. Thus, one might expect that the main dynamical features of the atmospheric response can be captured by a nondivergent barotropic vorticity equation model. Branstator (1985a,b), for example, found that a linear barotropic model could reproduce the structure of the midlatitude atmospheric response of NCAR's Community Climate Model to central tropical Pacific SST anomalies if it is forced by a vorticity source/sink in approximately the same geographical location as the SST anomaly. 
For stationary solutions, or in the case of very low frequency variability, one can neglect in the first approximation the time derivative in the linear barotropic equation resulting in the linear problem $\mathscr{C}(\bar{\psi}) \psi^{\prime}=\mathscr{F}^{\prime}$ where $\mathscr{A}$ is the barotropic operator linearized about the basic state $\bar{\psi}, \psi^{\prime}$ is the deviation of the stream function from the basic state and $\mathscr{F}^{\prime}$ is the anomalous forcing due to SST anomalies. The solution can be written in the form $\psi^{\prime}=\sum_{j} a_{j} \psi_{j}$ with scalar coefficients $a_{j}=\phi_{j} / \omega_{j}$ where $\omega_{j}$ and $\psi_{j}$ are the eigenvalues and the eigenvector of the operator $\&$ and scalar coefficients $\phi_{j}$ are the projections of the forcing term $\mathscr{F}$ ' on the eigenvectors $\psi_{j}^{*}$ of the adjoint opertor $\ell^{*}$. Thus the magnitude of the coefficients $a_{j}$ of the solution is proportional to the amplitude of the projection of the forcing $\mathscr{F}^{\prime}$ onto the adjoint eigenvector $\psi_{j}^{*}$ and is inversely proportional to the amplitude of the corresponding eigenvalue.

To compute normal mode of the linear barotropic operator the stream function at $500 \mathrm{hPa}$ averaged over winter months in the GCM experiments was used for the basic state $\bar{\psi}$. The eigenvalue problem was solved for the constant linear drag coefficient $1 / 7$ days $^{-1}$ and for the horizontal diffusion coefficient which corresponds to damping times for the shortest model scales of 0.65 days. Numerical tests indicated that the general structure of the normal modes is rather insensitive to the value of the horizontal diffusion. The fields were represented in spectral form and truncated at wave number 21 analogously to the ECHAM2/T21 model. The barotropic normal modes in the Northern Hemisphere, the basic state was antisymmetrically extrapolated into the Southern Hemisphere and only antisymmetric spherical harmonics were retained in the spectral presentation of all fields. By doing so we reduced the size of the complex nonsymmetric matrix to $231 \times 231$.

The normal modes presented in the following subsections are ordered according to the amplitude of the corresponding eigenvalues. Normal modes with smallest eigenvalues would mainly contribute into the solution of the linearized barotropic equation under the condition that the magnitude of projections of forcing onto the adjoint eigenvectors $\phi_{j}$ is of the same order for all $j$. For better comparison with the results from previous sections the stream function of normal modes was transformed to geopotential height by means of the balance equation $\nabla^{2} \Phi=\nabla \cdot f \nabla \psi$.

\subsection{Normal modes of the operator $\mathscr{b}$}

The first two normal modes of the linear operator $A$ computed for the winter climate in the GAGO experiment and the first normal mode of the observed climate are shown in Fig. 8. All normal modes appeared to be stable.

The first normal mode is nearly stationary with a time period $T=300$ days. The real part of it (Fig. 8a) resembles very much the first canonical patterns of $\mathrm{H} 500$ found in the GAGO run as well the first EOF of
H500 in the GAGO run. Negative anomalies are located over the northern parts of the North Atlantic and North Pacific Oceans. Positive anomalies are placed south of the negative anomalies as well as over the North American continent, southern Europe and over the Japan Sea. These aspects are common to the leading variability modes found in the GCM runs. The imaginary part (Fig. 8 b) has a positive anomaly around the north pole and negative anomalies over North America, the North Sea and eastern Siberia.

The second normal mode in the GAGO run (Fig. $8 c)$ is stationary. It is located mainly in the North Atlantic sector. Apart from a rather strong feature around the North Pole, the structure of the second normal mode is similar to the structure of the real part of the first normal mode in the North Atlantic. The second mode in moderate latitudes is also similar to the first canonical mode found in the MOGA run. The first two normal modes computed for the other GEM runs are very similar to the normal modes described. It seems that they contribute mainly to the monthly atmospheric variability and to the atmospheric response to the SST in the GCMs.

The first normal mode computed for the observed climate is shown in Fig. 8d. There is no obvious correspondence between this mode and the observed leading EOFs in Fig. 4 as it is the case for the GCM climate. Some similarity with the PNA-type pattern can still be found in the east Pacific/North America sector. In particular, negative anomalies are placed in the subtropical North Pacific and over the north of North America. Positive anomalies are found in the northeast of the North Pacific and in the southwest of the North Atlantic. The negative center over the east of Russia has, however, a much stronger amplitude and is placed further south and east as it is the case in the first observed EOF. The second normal mode (not shown) is nearly stationary and is similar to the first normal mode in the GAGO run.

Remarkably, the general structure at least of the first two barotropic normal modes is common to the structure of the leading variability atmospheric modes. Especially in the GCMs, where the first EOF is clearly dominant, the correspondence is relatively good. For the observed climate the results are less satisfactory. Note, however, that the observed basic state in the tropical area south of $20^{\circ} \mathrm{N}$ was derived in this study from the CONTROL climate so that the details of the basic flow in this region can influence the results of the normal mode analysis.

\subsection{Eigenvectors of the adjoint operator $\mathscr{A}^{*}$}

The scalar coefficients $\phi_{j}$ in the expansion of the external forcing $\mathscr{F}^{\prime}$ in terms of the eigenvectors of the operator $f^{\prime}$ are the projectons of the forcing onto the adjoint eigenvectors $\psi_{j}^{*}$ Thus, the spatial structure of the adjoint eigenvectors represents an anomalous vorticity forcing which excites the corresponding normal modes most efficiently. 

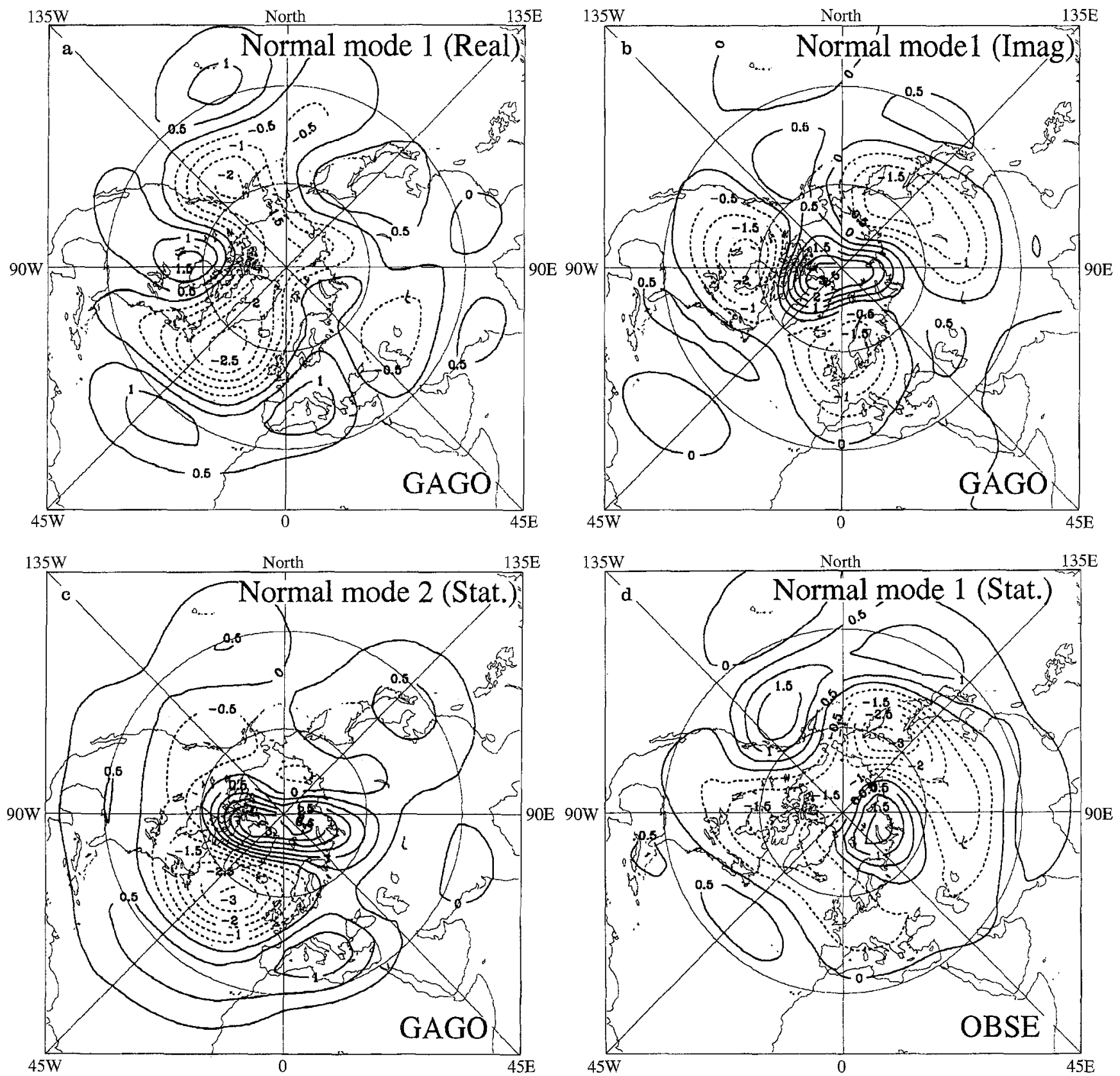

Fig. 8a-d. The first (a, real part; b, imaginary part) and the second (c, stationary mode) normal modes of the barotropic operator linearized about the winter climate of the GAGO run and the

The eigenvectors of the operator $\ell^{*}$ which correspond to the normal modes presented above are shown in Fig. 9. The real part of the first eigenvector (Fig. 9a) has anomalies with large amplitudes over the western North Pacific. The anomalies have the form of zonally oriented belts. In the imaginary part of the first adjoint mode (Fig. 9b), in the second adjoint eigenvector (Fig. $9 c)$ in the GAGO run and in the first adjoint mode of the observed climate (Fig. 9d) anomalies of large amplitude are found over the western parts of the both basins. The centers of action in the adjoint eigenvectors are in the vicinity of zones of strong baroclinic ac- tivity over both oceans. Shifting of the storm tracks in the north-south direction, and/or, intensification/weakening of transient eddy activity in these regions due to SST anomalies would lead to variations of the transient forcing of the time meqn circulation.

Metz (1989) investigated the relation between lowfrequency atmospheric variability and transient forcing on the base of six winters of ECMWF analysis. He applied canonical correlation analysis to the low-pass filtered stream function and the pattern that results from the effects of cyclone-scale eddies on the mean circulation. Low freuqency counterparts of the first two ca- 

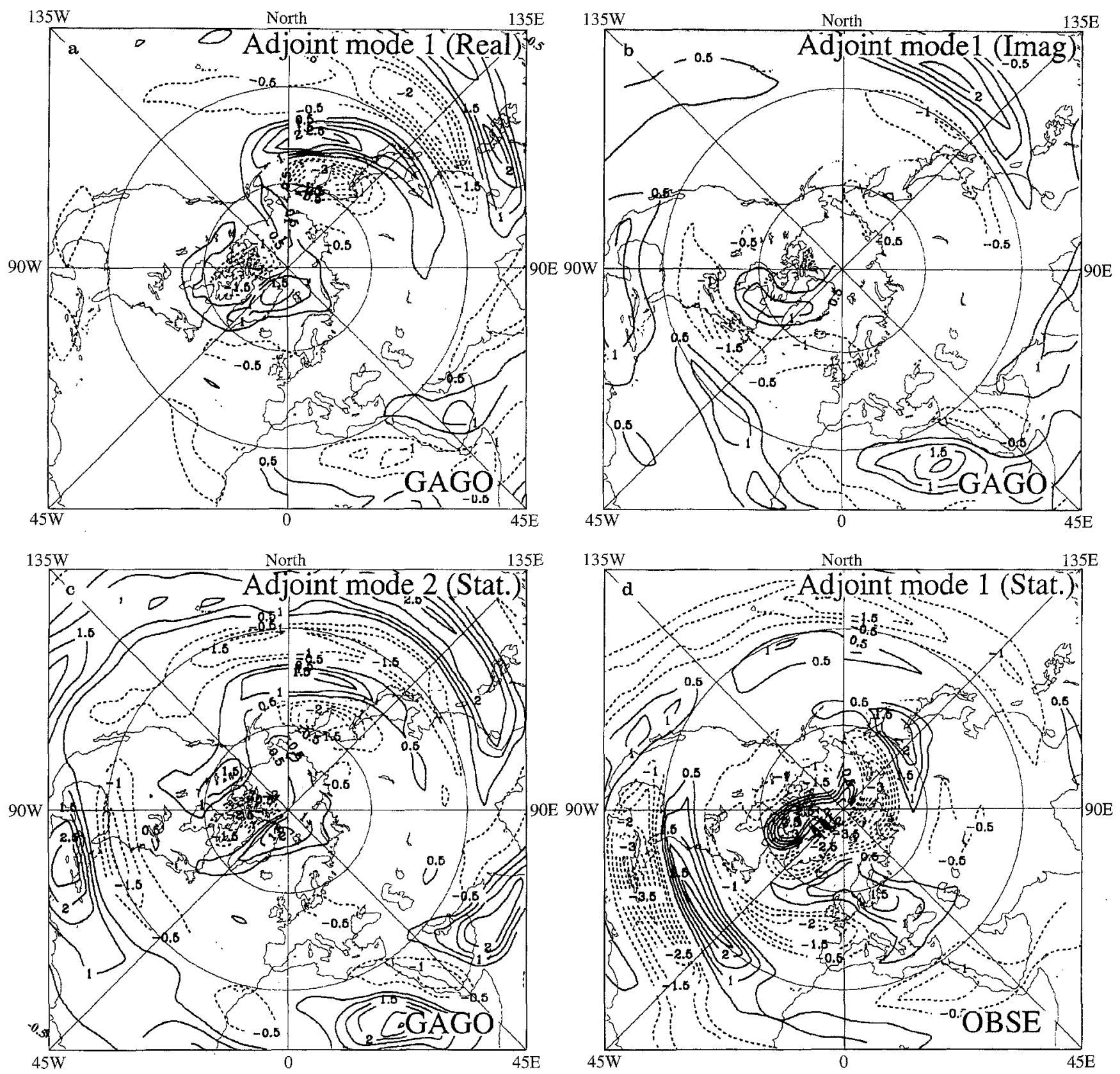

Fig. 9a-d. The first (a, real part; b, imaginary part) and the second (c, stationary) eigenvectors of the adjoint barotropic operator linearized about the winter climate of the GAGO run and the

first adjoint eigenvector of the observed climate (d, stationary). Contour interval is 0.5 . Zero line is omitted

nonical modes were of planetary scale. Canonical patterns, which represented the eddy effects, were locally concentrated over the North Pacific and North Atlantic. The canonical patterns of eddy forcing had a similar elongated structure as the adjoint eigenvectors described above.

\section{Summary and discussion}

The atmospheric winter time interannual variability in several 19-year GCM runs with different types of SST forcing was examined by means of the EOF analyis.
The leading modes of atmospheric variability in GCMs were found to be substantially different from the observed ones. In particular, the first model EOF of $\mathrm{H} 500$ has a global structure with negative anomalies over the northern parts of the North Atlantic and North Pacific and in polar regions and positive anomalies roughly south of the negative ones. The first observed EOF, on the contrary, has its main anomalies over the North Pacific. In addition, the first two EOFs in the GCM are more strongly separated than in the observations. Thus, the details of the atmospheric response in the extratropics are probably not quite correctly reproduced compared to the observations. Nevertheless, the GCM 
results still demonstrate the potential effect of the SST forcing in different geographical regions on the atmospheric circulation.

The CCA was used to find the best correlated pair of patterns of SST in the North Atlantic and Pacific and atmospheric circulation in the Nothern Hemisphere. In the GAGO and MOGA experiments the atmospheric response over the North Atlantic area was found to be a part of global patterns. The best correlated pattern of Northern Hemisphere geopotential height at $500 \mathrm{hPa}$ in the GAGO run is global and is related to SST anomalies in the North Atlantic and the North Pacific. It resembles the leading variability mode in the GAGO run. The statistical significance of the canonical correlation for the GAGO1 mode is very high. The variance explained by the first canonical pattern of H500 is much higher than for the other experiments (1.6 times as large as in the CONTROL run and almost twice as large as in the MOGA and the TOGA runs). This mode is quite robust and insensitive to the number of the EOFs and the choice of geographical regions or SST anomalies used in the CCA.

In the MOGA experiment the atmospheric signal in the Northern Hemisphere is weaker than in the GAGO run. The first canonical pattern of H500 differs from the GAGO1 mode, despite the fact that the corresponding canonical pattern of SST is similar in midlatitudes to the first canonical SST pattern in the GAGO run. The variance explained by the MOGA mode is approximately the same in all GCM integrations, including the CONTROL run. It seems that in the MOGA run another type of atmospheric variability mode is excited by extratropical SST anomalies. However the signal is weak and probably not very stable.

The El Niño type mode was found as the first canonical pair of patterns in the TOGA run and as the second canonical mode in the GAGO run. The variances explained by the GAGO2 and the TOGA1 atmospheric modes in both runs are about twice as large as the magnitude of those in the CONTROL integration and the MOGA run. It seems that for the El Niño mode, tropical SST anomalies are of essential importance which is consistent with the previous results (e.g. Graham et al. 1994). The tropical SST anomalies in the Pacific associated with the El Niño phenomenon have, on the contrary, no influence on the GAGO1 mode in the GAGO experiment.

Neither the MOGA and the TOGA runs alone, nor their linear combination is able to reproduce the signal found in the GAGO run as the first canonical mode. The nonlinear effects and the interactions between midlatitudes and tropics seem to be important. Artificial meridional SST gradients at $25^{\circ} \mathrm{N}-30^{\circ} \mathrm{N}$ in the MOGA and the TOGA runs probably influence the atmospheric response in these GCM experiments. The last effect represents a real problem in experiments such as GAGO-MOGA-TOGA that attempt to investigate the relative importance of the SST forcing in the middle latitudes and in the tropics. In particular, in the MOGA run the first canonical pattern of H500 seems to be related to the artificial SST meridional gradients in the North Atlantic and North Pacific at $25^{\circ} \mathrm{N}-$ $30^{\circ} \mathrm{N}$.

A normal mode analysis was performed in order to explain the discrepancies between the leading atmospheric variability modes in the GCM and in the observations. The leading normal modes of the barotropic operator linearized about the winter climate at $500 \mathrm{hPa}$ in the GCMs were compared with the canonical modes and the EOFs. The first two normal modes in the GCM runs were found to have some similarity to the leading variability modes in the GCMs. In particular, the spatial structure of the real part of the first nearly stationary mode is very similar to the structure of the GAGO1 mode. The second normal mode is, at least qualitatively, similar to the MOGA1 canonical mode.

The first normal mode for the observed winter climate differs significantly from the first two normal modes in the GCMs. The resemblance of the observed first normal mode to the leading mode of the observed variability is, however, relatively weak. The largest anomalies in the observed first normal mode are located in the North Pacific. Some similarity to the observed first EOF is found in the eastern North Pacific/ North America sector.

Eigenvectors of the adjoint operator display the structure of the forcing which excites the normal mode most efficiently. Leading adjoint vectors have strong zonally elongated anomalies over the eastern parts of the North Pacific and the North Atlantic oceans in the extratropics i.e. in the regions where the strongest transport of the heat and momentum occur in the troposphere. The variability of the storm tracks which is partly related to the SST variability in the extratropics can significantly influence the variability of nearly resonant barotropic normal modes.

Acknowledgements. The author thanks Professor V. P. Dymnikov and Dr. H. von Storch very much for numerous fruitful discussions on the topic and valuable suggestions for improving the paper. Special thanks go to Victor Ocaña and Gabriele Hegerl whose comments after the reading of the preliminary versions of the paper were very useful. The procedure for computing unbiased canonical correlation values was kindly supplied by Eduardo Zorita.

\section{Appendices}

\section{A Monte-Carlo significance tests for canonical correlations}

To define the statistical significance of canonical correlations 200 CCAs were performed for each GCM run under exactly the same conditions as described in Section 3 and 4 (December, Janury, February, 5 EOFs for each variable) and with the same data except tha the data field were randomly rearranged in time so that the correlations between two fields were caused by chance. The significance level $x \%$ of the first, or any other, canonical correlation $r$ was defined as the percentage of all 200 CCA cases with the corresponding 
Table 1. The values of the first and the second canonical correlations and of the pattern correlation between the first atmospheric canonical pattern and the first EOF together with the statistical significance levels (in brackets), as obtained from Monte-Carlo simulations

\begin{tabular}{llllll}
\hline CCA & GAGO: & MOGA: & GAGO: & MOGA: & TOGA: \\
& SLP (NA) & SLP (NA) & H500 (NH) & H500 (NH) & H500 (NH) \\
& vs. SST (NA) & vs. SST (NA) & vs. SST (GL) & SST (ML) & vs. SST (TR) \\
\hline 1st & $0.66(99.5 \%)$ & $0.54(80 \%)$ & $0.66(98.5 \%)$ & $0.61(97 \%)$ & $0.66(98.5 \%)$ \\
2nd & $0.38(70 \%)$ & $0.44(90 \%)$ & $0.61(100 \%)$ & $0.47(98 \%)$ & $0.40(80 \%)$ \\
pat. cor. & $0.92(100 \%)$ & $0.35(50 \%)$ & $0.89(97.5 \%)$ & $0.66(70 \%)$ & $0.06(50 \%)$ \\
\hline
\end{tabular}

NA, GL, ML and TR are the abbreviations for North Atlantic, Global, Middle Latitudes and Tropics, respectively

Table 2. The first and the second canonical correlations in the GCM runs and their corrected unbiased values

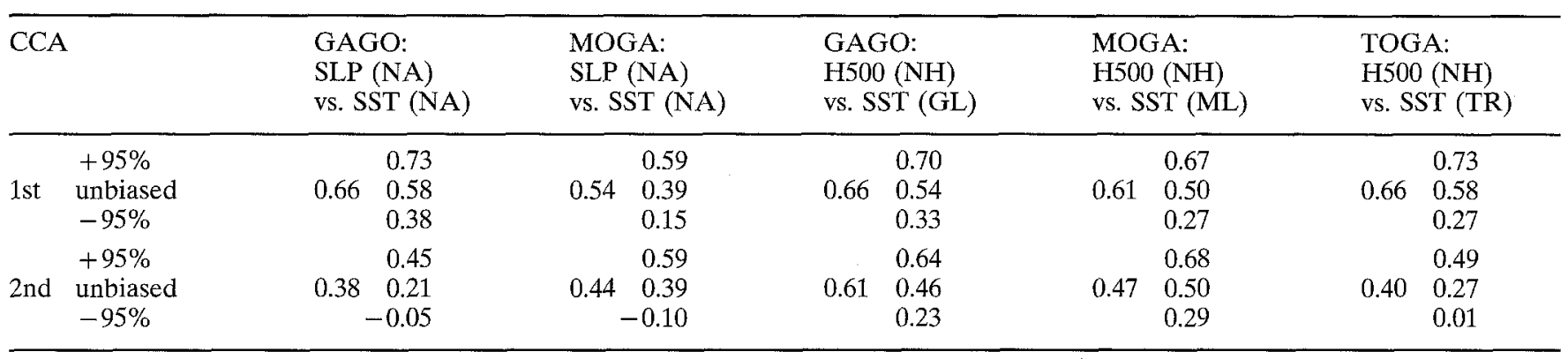

The 95\% significance intervals are depicted above and below the unbiased correlations. NA, GL, ML and TR are the abbreviations for North Atlantic, Global, Middle Latitudes and Tropics, respectively

canonical correlations smaller than $r$. For example, in the case of the CCA of North Atlantic SST versus North Atlantic SLP in the GAGO run the first canonical correlation was smaller than 0.66 in 199 CCAs, i.e. in $99.5 \%$ of all CCA cases. Thus, this value was considered to be $99.5 \%$ significant in this particular case.

Another test was performed to estimate the expectation of the fact that the leading mode of the atmospheric variability would appear as the first canonical pattern in the CCA. For this purpose the pattern correlations between the first EOF of the atmospheric variability and the first canonical patterns obtained in the Monte-Carlo CCA simulations described above were claculated. The statistical significance of the pattern correlation was defined in the same way as the statistical significance of the canonical correlations. Particularly, in the case of North Atlantic SST versus North Atlantic SLP in the GAGO run the pattern correlation between the first EOF of SLP in the North Atlantic and the first canonical pattern was smaller than 0.92 in all 200 CCAs $(100 \%)$.

Table 1 summarizes the results of the Monte-Carlo simulations for the GAGO, MOGA and TOGA runs.

\section{B Glynn and Muirhead's test}

Since the data sets are limited in time, covariance matrices involved in the calculation of canonical correlations are estimated only approximately. Thus, the canonical correlations obtained as eigenvalues of a ma- trix which is the product of the covariance and inverse autocovariance matrices are estimated with errors.

Glynn and Muirhead (1978) proposed a technique which provides corrected unbiased estimates of canonical correlations and their significance intervals. Input parameters for this procedure are the length of time series, the number of EOFs retained in the CCA and the values of all canonical correlations. In Table 2 the corrected values and their $95 \%$ significance intervals for the first and the second canonical correlations in the GAGO, MOGA and TOGA runs are presented. For example, the unbiased value of the first canonical correlation between SLP and SST in the North Atlantic in the GAGO run is 0.58 compared to its original value 0.66 . The $\pm 95 \%$ interval in this case in 0.38 0.78 .

\section{References}

Barnett TP, Preisendorfer R (1987) Origins and levels of monthly and seasonal forecast skill for United States surface air temperatures determined by canonical correlation analysis. Mon Weather Rev 115:1825-1850

Barnett TP, Heinz H-D, Hasselmann K (1984) Statistical prediction of seasonal air temperatures over Eurasia. Tellus 36A: $132-146$

Barnett TP, Latif M, Kirk E, Roeckner E (1991) On ENSO Physics. J Atmos Sci 4:487-515

Branstator G (1985a) Analysis of general circulation model seasurface temperature anomaly simulations using a linear model. Part I: forced solutions. J Atmos Sci 42:2225-2241 
Branstator G (1985b) Analysis of general circulation model seasurface temperature anomaly simulations using a linear model. Part II: eigenanalysis. J Atmos Sci 42:2242-2254

Dymnikov VP, Filin SK (1985a) A correlation study of extratropical sea surface temperature anomalies and heating anomalies based on data from the First GARP Global Experiment. Reprint of the Department of Numerical Mathematics of the USSR Academy of Sciences 83, Moscow, USSR (in Russian)

Dymnikov VP, Filin SK (1985b) Numerical simulation of the atmospheric response to sea surface temperature anomalies in the North Atlantic. Reprint of Department of Numerical Mathematics of the USSR Academy of Sciences 84, Moscow, USSR (in Russian)

Glynn W, Muirhead R (1978) Influence in canonical correlation analysis. J Multivar Anal 8:468-478

Graham NE, Barnett TP, Wilde R, Ponater M, Schubert S (1994) On the roles of tropical and mid-latitude SSTs in forcing interannual to interdecadal variability in the winter Northern Hemisphere circulation. J Clim 7:1416-1441

Hoskins BJ, Karoly DJ (1981) The steady linear response of a spherical atmosphere to thermal and orographic forcing. J Atmos Sci 3:1179-1196

Kharin VV (1995) The atmospheric response to North Atlantic sea surface temperature anomalies in GCM experiments. Max-Planck-Institut für Meteorologie, Hamburg, Examensarbeit 28

Kushnir Y, Lau N-C (1992) The general circulation model response to a North Pacific SST anomaly: dependence on time scale and pattern polarity. J Clim 5:271-283

Lau N-C (1988) Variability of the observed midlatitude storm tracks in relation to low-frequency changes in the circulation pattern. J Atmos Sci 45:2718-2743

Lau N-C, Nath MJ (1990) A general circulation model study of the atmospheric response to extratropical SST anomalies observed in 1950-79. J Clim 3:965-989

Lau N-C, Nath MJ (1994) A modeling study of the relative roles of tropical and extratropical SST anomalies in the variability of the global atmosphere-ocean system. J Clim 7:1184-1207

Metz W (1989) Low-frequency anomalies of the atmospheric flow and the effects of cyclone-scale eddies: a canonical correlation analysis. J Atmos Sci 46:1026-1041

Namias J (1964) Seasonal persistence and recurrence of European blocking during 1958-1960. Tellus 16:394-407

Namias J (1978) Multiple causes of the North American abnormal winter 1976-1977. Mon Weather Rev 106:279-295
Palmer TN, Sun Z (1985) A modelling and observational study of the relationship between see surface temperature in northwest Atlantic and the atmospheric general circulation. Q J R Meteorol Soc 111:947--975

Pitcher EJ, Blackmon ML, Bates GT, Mu S (1988) The effect of North Pacific sea surface temperature anomalies on the January climate of a general circulation model. J Atmos Sci 45:173-188

Ponater M, König W (1991) Interannual circulation regime fluctuations and their effect on intraseasonal variability. In: Sausen R (ed) Meteorologisches Institut Universität Hamburg Large Scale Atmospheric Modelling, Rep 9

Ratcliffe RAS, Murray R (1970) New lag associations between North Atlantic sea temperature and European pressure applied to long-range weather forecasting. Q J R Meteorol Soc 96:226-246

Roeckner F, Arpe K, Bengtsson L, Brinkop S, Dümenil L, Esch M, Kirk E, Lunkeit F, Ponater M, Rockel B, Sausen S, Schlese U, Schubert S, Windelband M (1992) Simulation of the present-day climate with the ECHAM model: impact of model physics and resolution. Max-Planck-Institut für Meteorologie, Hamburg, Rep 93

Ting M (1991) The stationary wave response to a midlatitude SST anomaly in an idealized GCM. J Atmos Sci 48:12491275

Wallace JM, Gutzler DS (1981) Teleconnections in the geopotential height field during the Northern Hemisphere winter. Mon Weather Rev 106:296-310

Wallace JM, Jiang Q (1987) On the observed structure of the interannual variability of the atmosphere/ocean climate system. In: Cattle H (ed) Atmospheric and ocean variability, Roy Meteor Soc, $17-43$

Wallace JM, Smith C, Jiang Q (1990) Spatial patterns of atmosphere/ocean interaction in the Northern winter. J Clim 118:990-998

Wallace JM, Smith C, Bretherton CS (1992) Singular value decomposition of wintertime sea surface temperature and 500 hPa height anomalies. J Clim 5:561-576

Webster PJ (1981) Mechanisms determining the atmospheric response to sea surface temperature anomalies. J Atmos Sci 38:554-571

Zorita E, Kharin VV, von Storch H (1992) The atmospheric circulation and sea suface temperature in the North Atlantic area in winter: their interaction and relevance for Iberian precipitation. J Clim 5:1097-1108 